\title{
APRENDIZAGEM APOIADA POR COMPUTADOR: ENSINANDO GEOMETRIA PLANA ATRAVÉS DE IMAGENS ORBITAIS
}

\author{
Karen Henn Gil, Pontifícia Universidade Católica do Rio Grande do Sul (PUCRS) - \\ karenhenn@ig.com.br \\ Thiago Bazzan, Pontifícia Universidade Católica do Rio Grande do Sul (PUCRS) - \\ thiago.bazzan@pucrs.br
} Valderez Marina do Rosário Lima, Pontifícia Universidade Católica do Rio Grande do
Sul (PUCRS) - valderez.lima@ pucrs.br

\author{
Regis Alexandre Lahm, Pontifícia Universidade Católica do Rio Grande do Sul \\ (PUCRS) - lahm@pucrs.br
}

RESUMO: O ensino de geometria plana, embora seja um conteúdo de relevância, não vem recebendo a devida importância no ensino fundamental. Esta pesquisa tem por objetivo apresentar uma proposta inovadora que utiliza imagens de satélites disponíveis no software Google Earth ${ }^{T M}$, para a construção de conhecimentos referentes às medidas de distância, formação de figuras geométricas e determinação de seus perímetros. A metodologia consistiu na realização de um conjunto de atividades com duas turmas de $5^{\mathrm{a}}$ série durante as aulas de matemática em contexto de unidade de aprendizagem. Os resultados das atividades promoveram o desenvolvimento de competências através da utilização das ferramentas disponíveis no software.

Palavras-chave: geometria plana, sensoriamento remoto, unidade de aprendizagem.

\section{COMPUTER SUPPORTED LEARNING: TEACHING PLANE GEOMETRY THROUGH ORBITAL IMAGES}

ABSTRACT: Despite being a relevant subject, plane geometry teaching has not received deserved attention in elementary schooling. The aim of this study was to present an innovating proposal, by using the software Google Earth $^{\mathrm{TM}}$ in the construction of the basic concepts of plane geometry, namely, distance measurements knowledge, geometric shapes and determination of its perimeters. For this, we performed a set of activities with two 5th grade groups, during the mathematics lessons in the context of learning units. This result fostered research and the development of skills through the use of tools available in the software.

Keywords: plane geometry, remote sensing, learning unit.

\section{INTRODUÇÃO}

O ensino da matemática faz parte de discussões nos meios educacionais no sentido de enfatizar sua importância para que esteja voltado a aspectos sociais, metodológicos e psicológicos, procurando apresentar uma visão menos conteudista.

Nesta perspectiva, é perceptível que, para a maioria dos alunos da $5^{\mathrm{a}}$ a $8^{\mathrm{a}}$ série do ensino fundamental, assim como do ensino médio, a matemática seja de difícil compreensão e o estudo desta disciplina acabe causando certo desconforto e resultando, muitas vezes, na retenção escolar destes alunos (Brasil, 1998; Neuhaus e Almeida, 2004; Santos, 2004; Vasconcelos, 2009). 
Assim, novas alternativas de construção do conhecimento devem ser propostas visando ampliar o interesse e a motivação por parte dos discentes em participar, de forma ativa, como sujeitos deste processo construtivo.

$\mathrm{O}$ enfoque desta pesquisa centra-se no ensino de geometria plana que, por se tratar de um tema geralmente abordado no final do ano letivo, normalmente não é contemplado adequadamente, o que vem mudando, haja visto que os livros didáticos já contemplam geometria intercalada com outros conteúdos da disciplina de matemática (aritmética e álgebra).

A aprendizagem dos conceitos de geometria plana com o uso do software Google Earth ${ }^{T M}$ é importante na medida em que ele permite ao professor a elaboração de estratégias de ensino numa perspectiva de construção de conhecimentos ao colocar em diálogo conteúdo conceitual, cotidiano dos alunos e tecnologias (Brasil, 1998).

Dessa forma, esta pesquisa tem por objetivo apresentar uma proposta inovadora que utiliza imagens de satélites disponíveis no software Google Earth ${ }^{T M}$, para a construção de conhecimentos referentes às medidas de distância, formação de figuras geométricas e determinação de seus perímetros. Esta pesquisa foi realizada com duas turmas de $5^{\mathrm{a}}$ série em uma escola estadual localizada no município de Porto Alegre, estado do Rio Grande do Sul.

\section{FUNDAMENTAÇÃO E REFLEXÃO TEÓRICA}

\subsection{Importância do Ensino de Matemática e da Geometria}

Muitos são os estudos sobre métodos aplicáveis ao ensino de matemática, com o intuito de ampliar a aprendizagem dos conteúdos conceituais dessa disciplina (Vasconcelos, 2009; Moser e Portanova, 2008). E, por conta dessa preocupação de professores e pesquisadores, existe um movimento de mudanças na forma de organizar o ensino de matemática. Tal movimento apresenta como contraponto a resistência de alguns professores em arriscar o uso de novos métodos de ensino pelo receio de perder o controle no que tange as curiosidades e dificuldades que podem ser expressas pelos alunos, e também pela ausência de tempo para trabalhar os conteúdos.

O ensino de matemática, no que se refere ao conteúdo de geometria, apesar do reconhecimento de sua relevância, tem sido pouco explorado nos currículos contemporâneos. Arbach (2002, p.17) elucida questões sobre o abandono do ensino da geometria, e afirma que este fenômeno ocorre também em outros países, não só no Brasil. Em sua pesquisa, as causas apresentadas pelo descaso com o ensino da geometria no ensino fundamental são: de ordem política / ideológica; de problemas de formação de professor; de ordem relacionadas à abordagens no livro didático, como omissões de tópicos de geometria; das lacunas deixadas pelo movimento da matemática moderna, entre outras.

Pavanello (1993, p.15) assinala que: do ponto de vista da educação matemática, é necessário acrescentar que o ensino da geometria continua ocorrendo nas escolas particulares (como também nas academias militares). Trabalhada sob orientações diversas, integrada ou não aos demais ramos da matemática, a geometria continua presente nos currículos escolares, e os professores de matemática não podem deixar de abordá-la, mesmo se sua formação for de tal modo deficiente que os impeça de efetuar um trabalho de melhor qualidade. 


\subsection{Tecnologia na Educação}

A utilização das novas tecnologias no ensino e na aprendizagem pode trazer melhorias bastante significativas para a educação. Mas, para isso, as aulas devem ser planejadas e organizadas, com o cuidado para não continuarem no mesmo modelo de ensino de antes, no qual o aluno continua receptor das informações do professor.

D'ambrósio (1998, p.16) sustenta que uma escola de classe pobre necessita expor seus alunos a esses equipamentos que estarão presentes em todo mercado de trabalho no futuro imediato. Se uma criança de classe pobre não vê na escola um computador, como jamais terá oportunidade manejá-lo em sua casa, estará condenada a aceitar os piores empregos que se lhe ofereçam.

Para Moran (2001, p.103) os princípios da tecnologia da informação auxiliam o entendimento de que a informática pode ser instrumento afinado perfeitamente com os projetos de aprendizagem e com as práticas pedagógicas, desde que haja um gerenciamento adequado dos recursos informatizados. A inovação não está restrita ao uso da tecnologia, mas também, à maneira como o professor vai se apropriar desses recursos para criar projetos metodológicos que superem a reprodução do conhecimento e levem à produção do conhecimento.

Diante disso, acredita-se que a tecnologia pode contribuir para uma reestruturação do ensino que beneficie o protagonismo dos sujeitos nesse processo. Mas isto somente ocorrerá se os profissionais tiverem como foco a mudança em sua prática profissional, empenhando-se pessoalmente na busca por qualificação. A informatização está ao alcance dos docentes, entretanto, é preciso saber utilizá-la, para não acabar por repetir as mesmas propostas que estão norteando o ensino atualmente.

De acordo com Giraffa (2009, p. 28), cabe ao professor criar novas metodologias, explorar os espaços virtuais e as suas possibilidades. A matemática é uma das áreas em que se encontra o maior número de softwares disponíveis para auxiliar no processo ensino e aprendizagem.

\subsection{Sensoriamento Remoto}

O sensoriamento remoto pode favorecer igualmente muitas possibilidades para a educação em matemática, como tornar o ensino de geometria acessível e contextualizado em um ambiente que desperte o interesse dos alunos na realização das tarefas, oportunizando, assim, a visualização e a percepção do espaço de onde estão, através de imagens orbitais, bem como provocar a busca por informações.

O sensoriamento remoto é uma técnica agregadora e multidisciplinar, servindo de ferramenta para as áreas de matemática, física, química, biologia e das ciências da Terra e da computação, e a sua aplicação está abrangendo cada vez mais áreas do conhecimento (Figueiredo, 2005; Novo, 1999).

Acredita-se que esta tecnologia avançada, na sala de aula, pode beneficiar consideravelmente o aprendizado significativo em matemática, levando-se em conta que o contexto, no qual o aluno está inserido na proposta, contribui para a visualização das 
formas geométricas, no espaço geográfico e facilita a construção dos conceitos de ponto, reta e plano.

Segundo Santos et al. (2008, p.119), utilizar do sensoriamento remoto como recurso didático-pedagógico, como ferramenta auxiliar em unidades de aprendizagem, pode facilitar a construção de conhecimentos sobre determinado conteúdo. A utilização desta técnica oportuniza a percepção dos locais por onde os alunos andam diariamente, quando saem de casa para ir à escola.

\subsection{Unidade de Aprendizagem}

A unidade de aprendizagem, doravante denominada UA, consiste em atividades elaboradas estrategicamente, com o propósito de reconstrução de conceitos, os quais evoluem de forma gradual, conforme o avanço do grupo.

De acordo com Freshi e Ramos (2008, p.79), a UA possibilita atingir objetivos educacionais relevantes, como promover a capacidade de pensar e de solucionar problemas e desenvolver a autonomia e a autoria. Estas atividades, realizadas em contexto de UA, oportunizam também a pesquisa e as trocas entre os participantes, permitindo a participação criativa dos alunos, visto ser esta proposta de ensino nãolinear nem sequencial, incentivando a busca do aluno por informações.

Moraes et al. (2004, p.11) apresentam a seguinte definição para a pesquisa em sala de aula: a pesquisa em sala de aula pode ser compreendida como um movimento dialético, em espiral, que se inicia com o questionar dos estados do ser, fazer e conhecer dos participantes, construindo-se a partir disso novos argumentos que possibilitam atingir novos patamares desse ser, fazer e conhecer, estágios esses então comunicados a todos os participantes do processo.

Moran et al. (2001, p. 90) entendem o ensino com pesquisa como um processo educativo que necessita de um professor que perceba o aluno como um parceiro, sujeito do mesmo processo, um questionador, um investigador, que precisa alicerçar procedimento para desenvolver raciocínio-lógico, criatividade, posicionamento, capacidade produtiva e cidadania.

A UA é estruturada com atividades que instigam o aluno a fazer pesquisa em sala de aula. Conforme Freschi e Ramos (2008, p. 80), a elaboração da UA baseia-se na matriz conceitual e no diálogo, na leitura e na escrita, elementos fundamentais para que os alunos desenvolvam a organização do pensamento, a comunicação e a capacidade de argumentação.

De acordo com Moraes et al. (2004, p.139), o verdadeiro produto da educação pela pesquisa é sua qualidade político transformadora. Na medida em que a educação pela pesquisa promove sujeitos autônomos e capazes de decisão própria, possibilita a transformação das realidades em que estão inseridos. Isto é, fazer com que os assuntos, tratados em sala de aula, não tenham um fim ou uma utilização apenas na escola, mas, sim, um significado para a formação de cada um dos seus alunos, enquanto sujeitos.

\section{MATERIAIS E MÉTODOS}

A pesquisa foi desenvolvida durante o $2^{\circ}$ trimestre do ano de 2011, apresenta como sujeitos da pesquisa, alunos de duas turmas de $5^{a}$ série, totalizando 25 alunos de uma escola estadual de ensino fundamental, situada na zona norte do município de Porto Alegre, estado do Rio Grande do Sul. 
A pesquisa foi realizada com base na abordagem qualitativa e quantitativa, já que estes métodos, juntos, proporcionam uma melhor compreensão do fenômeno estudado. A metodologia de pesquisa qualitativa visou à compreensão dos fatos observados, juntamente com a interpretação do material coletado. A metodologia de pesquisa quantitativa ocupou-se em quantificar dados por meio de materiais que podem ser obtidos com entrevistas, questionários, técnicas de estatística.

Os materiais utilizados para a pesquisa foram questionários, sucatas e imagens de satélite. Os questionários e sucatas foram utilizados para o levantamento de conhecimentos prévios sobre as figuras geométricas. As imagens de satélite foram obtidas no software Google Earth ${ }^{T M}$ e utilizadas para o ensino de matemática, enfocando a construção de conhecimento em geometria plana, por meio de identificação das figuras geométricas em situações cotidianas.

Os instrumentos de coleta de dados para análise foram: diário de campo, observação direta, filmagem de alguns momentos das atividades, entrevista semiestruturada e o material construído pelos alunos durante as UA. Para a análise dos dados coletados, foram selecionadas as anotações do diário, e as tarefas realizadas na UA, para sua interpretação, utilizando-se a metodologia da análise textual discursiva de natureza qualitativa, que possui, conforme Moraes e Galiazzi (2007, p. 7), a finalidade de produzir novas compreensões sobre os fenômenos e discursos.

As atividades foram distribuídas de forma que o primeiro e segundo encontros foram constituídos de tarefas de verificação dos conhecimentos prévios. Já nos seguintes, do terceiro ao sétimo encontro, as atividades foram centradas na utilização do software e de seus recursos para a aprendizagem. No oitavo e último, foi realizada uma atividade individual, a fim de verificar a aplicação, ou não, dos conhecimentos. As atividades são apresentadas no Quadro 1.

Quadro 1 - Descrição das atividades

\begin{tabular}{|l|l|}
\hline Atividade 1 & Exploração de questões sobre ponto, reta e plano \\
\hline Atividade 2 & Identificação de figuras geométricas nas sucatas coletadas \\
\hline Atividade 3 & Exploração do software Google Earth \\
\hline Atividade 4 & Utilização dos aplicativos de marcar e ligar pontos \\
\hline Atividade 5 & Construção de figuras planas \\
\hline Atividade 6 & Diferenças entre triângulos e quadriláteros \\
\hline Atividade 7 & Cálculo de perímetro de triângulos e quadriláteros \\
\hline Atividade 8 & Avaliação final \\
\hline
\end{tabular}

\section{RESULTADOS E DISCUSSÃO}

\subsection{Unidade de Aprendizagem 1}

A UA 1 correspondeu ao levantamento de conhecimentos prévios a partir da exploração de questões sobre ponto, reta e plano. As tarefas tiveram início com questões de verificação de conhecimentos prévios, visando à percepção dos conhecimentos já construídos em vivências anteriores.

Este foi o ponto de partida para a reconstrução dos conceitos. Cada aluno recebeu uma folha contendo questões nas quais era necessário escrever ponto, reta e plano de acordo com a semelhança, ao lado de sentenças como: assento de cadeira, 
estrela no céu, fio esticado entre dois postes, entre outros objetos que eles visualizam cotidianamente, reconhecer e diferenciar triângulos, reconhecer e diferenciar quadriláteros e cálculo de área e perímetro de figuras planas.

Os resultados do exercício mostraram que na turma " 1 " a média de acertos foi de 3,85 com desvio-padrão de 2,19 e coeficiente de variação igual a $57,01 \%$. A turma " 2 " apresentou média de acertos de 4,58, desvio-padrão de 2,04 e coeficiente de variação de $44,54 \%$.

\subsection{Unidade de Aprendizagem 2}

A UA 2 correspondeu a uma atividade para o levantamento de conhecimentos prévios a partir da identificação das figuras geométricas formadas com sucatas coletadas pelos alunos da turma "1" e turma "2". O exercício tinha o propósito de avaliar o que eles já tinham aprendido sobre figuras. Esse exercício foi aplicado para planejar as atividades na sala de informática e, portanto, a ele não seria atribuído um grau de avaliação.

Para a realização do exercício, as sucatas foram dispostas em uma mesa no centro da sala para que os alunos analisassem as figuras geométricas que poderiam ser identificadas com estes objetos e fizessem dez relações entre os objetos e as figuras geométricas que conhecessem. Cada aluno recebeu uma folha em branco para fazer suas anotações. Para isso, os alunos podiam explorar o material a vontade.

Os resultados do exercício mostraram que a turma " 1 " apresentou uma média de acertos de 3,09, o desvio-padrão foi de 1,72 e o coeficiente de variação $55,66 \%$. A Turma " 2 " teve uma média de 2,45 acertos com desvio-padrão de 1,29 e coeficiente de variação igual a 52,69\%. Após as atividades de conhecimentos prévios, foram desenvolvidas as atividade de noções de geometria com o software Google Earth ${ }^{T M}$.

\subsection{Unidade de Aprendizagem 3}

A UA 3 correspondeu a exploração do software Google Earth ${ }^{T M}$. No primeiro momento foi oferecida uma atividade previa para que os alunos explorassem o software Google Earth ${ }^{T M}$ (Figura 1). Para isso, inicialmente se questionou se alguém já conhecia este software. As respostas foram quase todas negativas. Poucos alunos sabiam da existência do software, mas não tinham ideia do que se tratava. 


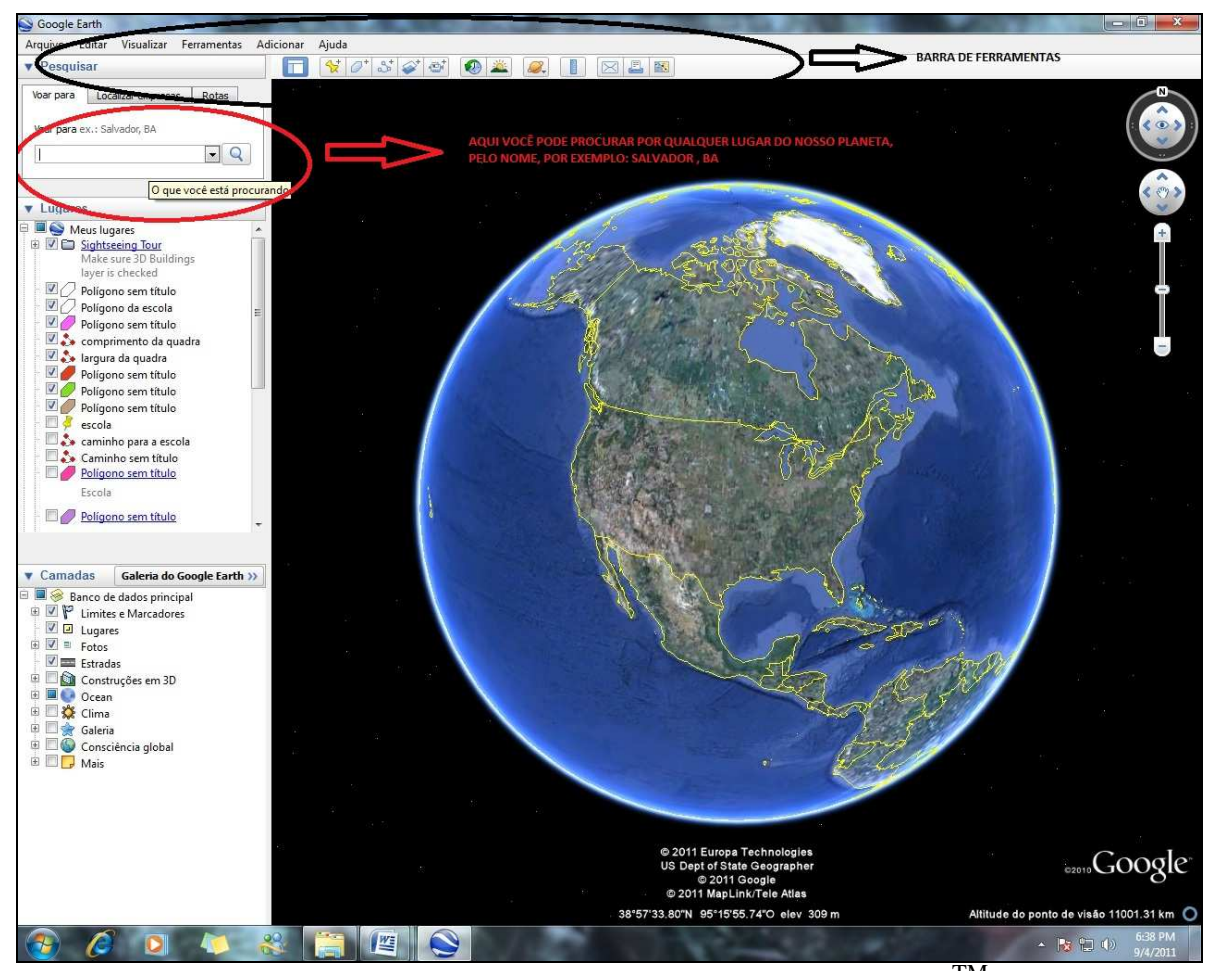

Figura 1- Tela inicial do software Google Earth ${ }^{\mathrm{TM}}$.

Foi explicado aos alunos que o software oportuniza localizar endereços que podem ser visualizados de várias formas de acordo com interesses próprios. Cada aluno ficou sozinho em um computador que já estava com o software Google Earth ${ }^{T M}$ na tela. Explicou-se que o endereço a ser localizado deveria ser inserido na caixa de texto situado à esquerda na porção superior da tela, conforme está destacado na Figura 1 por uma elipse vermelha onde diz "voar para".

Após este primeiro momento solicitou-se, aos alunos que ainda não haviam realizado nenhuma tentativa, que localizassem a escola e lugares que frequentam no entorno da escola. Os alunos observaram a quadra de esportes da escola, o formato de telhados dos prédios, formato de quadras de outras casas ao entorno da escola. Estes locais escolhidos nesta atividade foram utilizados nas tarefas seguintes, pois, como já era esperado, a curiosidade em ver os locais conhecidos e frequentados por eles foi evidente.

Nem todos tiveram essa facilidade em se localizar. E sempre que pediam ajuda, os colegas orientavam para procurarem as ruas, e seguir por elas até chegar ao local desejado. Muitos alunos precisaram de ajuda até para manusear o mouse. Com estes sentou-se ao lado e trabalhou-se junto até que conseguissem entender como funcionava.

Apesar de aprenderem rápido, observa-se que sabiam pouco sobre a utilização destes recursos. Este encontro foi muito gratificante no sentido de perceber $o$ entusiasmo dos alunos com as descobertas, e também suas expectativas para os próximos encontros.

\subsection{Unidade de Aprendizagem 4}


A UA 4 correspondeu a utilização das ferramentas para a construção de conhecimentos sobre ponto e reta no software Google Earth ${ }^{T M}$. Dentre as ferramentas, destacam-se os marcadores, cuja finalidade é fixar os pontos selecionados na imagem de satélite. Já a ferramenta régua foi utilizada para medir a distância e ligar os marcadores.

Os trabalhos realizados nesta unidade consistiram em ligar duas marcações e verificar a distância em metros. Os alunos traçaram as retas de comprimento e de largura em vermelho e observaram que esta figura é um retângulo, assim como o ponto do centro da quadra e o círculo. As imagens a seguir mostram os trabalhos dos alunos, na Figura 2 apenas três marcadores, e na Figura 3, dois marcadores ligados por uma reta.

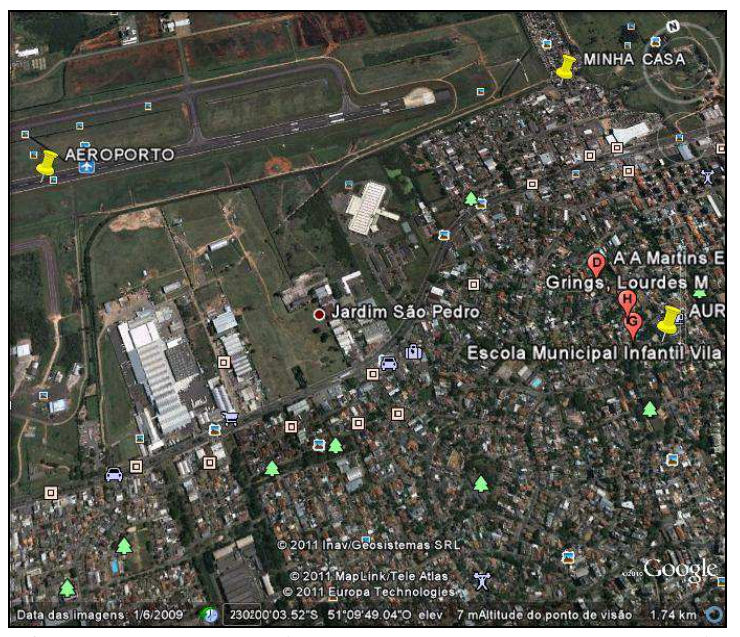

Figura 2 - Marcadores no aeroporto, na escola e na casa do aluno.

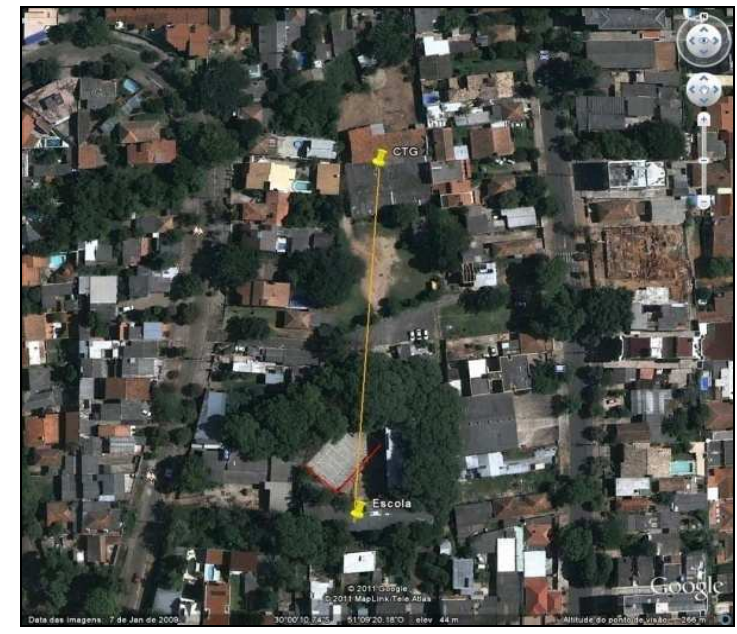

Figura 3 - Reta ligando os marcadores da escola e Centro de Tradições Gaúchas (CTG).

Neste encontro conseguiu-se trabalhar com noção de ponto e reta, que liga dois pontos. Este software possibilita um trabalho de imagens, no qual os alunos vão explorando por curiosidade e aprendendo por meio de questionamentos e na troca de ideias com os colegas.

\subsection{Unidade de Aprendizagem 5}

A UA 5 correspondeu a construção e percepção de figuras geométricas construídas no software Google Earth ${ }^{T M}$. Para isso foi solicitado aos alunos que ligassem 3 pontos não alinhados no software Google Earth ${ }^{T M}$. Nesta atividade era esperado que, ao unir os pontos, os alunos percebessem as figuras geométricas que se formavam. A primeira figura foi a construção de triângulos, como se pode observar na Figura 4. A partir disso, solicitou-se que analisassem as figuras juntos, observando as diferenças entre elas.

Chamou-se a atenção do grupo para que observassem a possibilidade de marcarem vários pontos em uma mesma reta. A partir dessa observação foram construídos os quadriláteros como mostra a Figura 5. 


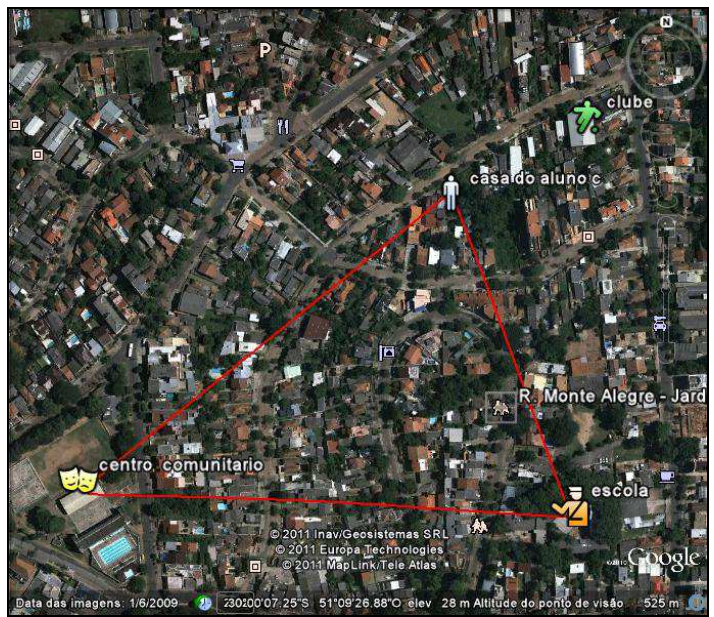

Figura 4 - Triângulo formado pelos pontos: escola, casa do aluno e centro comunitário.

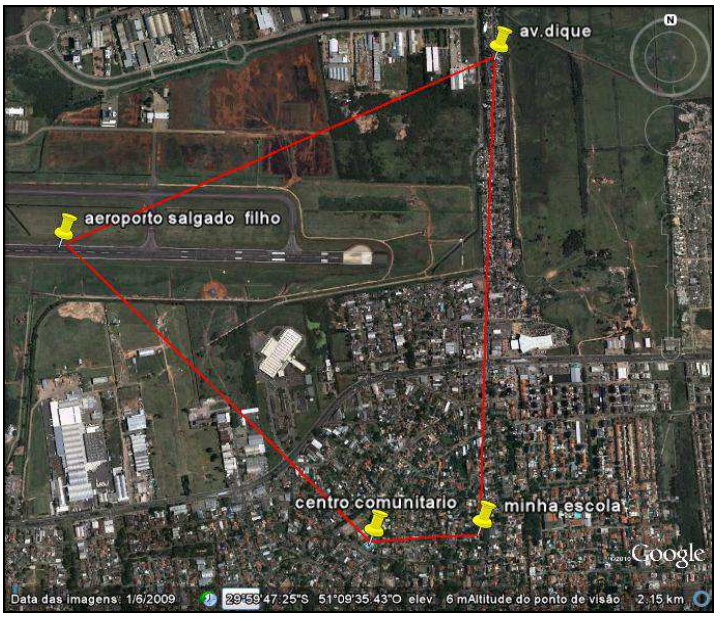

Figura 5 - Quadrilátero formado pelo aeroporto, centro comunitário, escola e vila.

Neste encontro dos alunos já conseguiam trabalhar com agilidade, utilizavam os marcadores com criatividade variando formas e cores, nomeavam e salvaram. Usavam a régua para medir a distância (metros), variavam as cores e também nomeavam.

\subsection{Unidade de Aprendizagem 6}

A UA 6 correspondeu a percepção das diferenças entre os triângulos construídos, e entre os quadriláteros construídos.

Solicitou-se que construíssem novamente figuras de três e de quatro lados, objetivando obter triângulos e analisar as diferenças entre eles, assim como com os quadriláteros. Foi muito interessante observar que procuravam marcar pontos na intenção de obter uma figura com os quatro lados iguais ou perto disso. Não se sentiam satisfeitos quando os lados apresentavam medidas muito diferentes, assim como com os triângulos. Em geral, os alunos preferiam quando ficava parecido com o triângulo retângulo, mesmo depois de todas as observações feitas no último encontro.

Assim que se formavam as primeiras figuras, questionou-se sobre a classificação dos triângulos em relação à medida dos lados, e pra isso tinham que registrar as medidas. Em relação ao nome dos triângulos, foi comum trocarem o escaleno com o equilátero, sendo o primeiro com todos os lados diferentes e o outro com todos os lados iguais. Neste encontro os alunos tiveram mais clareza sobre as figuras planas construídas e observadas. Estes conceitos são novidades, pois eles nunca tinham trabalhado com estes elementos de geometria nem com a nomeação dos triângulos.

\subsection{Unidade de Aprendizagem 7}

A UA 7 correspondeu ao cálculo de perímetro de figuras planas representadas pelos triângulos e quadriláteros. Para isso a pesquisadora trouxe algumas imagens de satélite, obtidas no software Google Earth ${ }^{T M}$ impressas, construídas pelo grupo.

Alunos que tiveram pouca interação com o grupo nestas atividades, ainda solicitavam a professora para confirmar se sua figura seria mesmo um triângulo. Em seguida começou-se a trabalhar com os quadriláteros observando as retas das figuras.

Esta aula foi produtiva porque os alunos já mostravam propriedade na elaboração de suas tarefas; já conseguiam construir figuras com rapidez e classificavam V. $10 \mathrm{~N}^{\mathrm{o}}$ 1, julho, 2012 
os triângulos com o número de lados e os quadriláteros com os pares de linhas paralelas. Algumas constatações foram feitas por eles sem muitas explicações como, por exemplo, que o quadrilátero com os quatro lados de mesma medida é quadrado, e o quadrilátero com dois pares de retas paralelas com mesma medida são os retângulos.

Observa-se que cada aluno desenvolve seu estilo de construção e observam o modo como seu colega trabalha, na intenção de aprender algo que lhe interessante por algum motivo, ou seja, quando tem alguma novidade que possam utilizar também.

\subsection{Unidade de Aprendizagem 8}

A UA 8 correspondeu a avaliação final e verificação de conhecimentos construídos. Para avaliar a aprendizagem, além das observações, foi aplicada uma atividade final semelhante com a atividade 1 do primeiro encontro, na qual foi solicitado aos alunos que respondessem ponto, reta ou plano. Esta UA foi realizada em três períodos de 45 minutos cada. Utilizou-se o projetor multimídia para mostrar os trabalhos realizados. Neste momento pediu-se que os alunos classificassem as figuras de acordo com seus conhecimentos.

A partir dos resultados observados nas UA, é possível afirmar que houve aprendizagem por parte de um número significativo de alunos das duas turmas, e nas observações das tarefas constatou-se que os alunos foram além do inicialmente proposto ao diferenciar os triângulos de acordo com as medidas dos lados.

\section{CONCLUSÕES}

Observou-se que o recurso tecnológico proposto e utilizado oportunizou uma abordagem dinâmica para o aprendizado da geometria plana, fazendo com que os alunos se envolvessem na construção das figuras geométricas, favorecendo um aprendizado efetivo. As duas turmas beneficiaram-se do trabalho proposto, uma mostrando mais maturidade, mas com o desafio de motivarem-se para o estudo, e a outra em fazer da agitação uma aliada na construção do conhecimento. $\mathrm{O}$ conteúdo matemático abordado nesta pesquisa mostra-se pertinente na medida em que os alunos obtêm noções de distâncias, medidas e diferenças entre figuras geométricas em seu contexto geográfico.

Não se tem a pretensão de querer provar que estes recursos tecnológicos aqui apresentados são a melhor forma de trabalhar noções de geometria, mas sim contribuir com a ideia de arriscar novas estratégias de ensino que motivem o aprendizado, contribuindo para o desenvolvimento das capacidades dos alunos. A observação de figuras geométricas planas em imagens orbitais motivou o aprendizado por parte dos alunos, uma vez que os mesmos visualizaram espacialmente as localidades onde eles circulam. Isto proporcionou a construção de conhecimentos de forma leve e eficaz, atingindo os objetivos além das expectativas iniciais da pesquisa.

\section{REFERÊNCIAS BIBLIOGRÁFICAS}

ARBACH, N. O ensino de geometria plana: o saber do aluno e o saber escolar. Dissertação (Mestrado em Educação Matemática). PUC/SP, 2002.

BRASIL, Ministério da Educação e Cultura. SEED. Parâmetros Curriculares Nacionais: terceiro e quarto ciclos do ensino fundamental, Matemática. 1998. 
D’AMBRÒSIO, U. Etnomatemática: arte ou técnica de explicar ou conhecer. São Paulo: Ática, 1998.

FIGUEIREDO, D. Conceitos básicos de sensoriamento remoto. 2005.

FRESHI, M; RAMOS, M. G. A reconstrução do conhecimento dos alunos sobre o ciclo da água por meio de unidade de aprendizagem. In: BORGES, R. M. R.; ROCHA FILHO, J. B.; BASSO, N. R. de S. (Org.). Avaliação e interatividade na educação básica em ciências e matemática. Porto Alegre: EdiPUCRS, 2008.

GIRAFFA, L. M. M. Uma odisséia no ciberespaço: O software educacional dos tutoriais aos mundos virtuais. Revista Brasileira de Informática na Educação, Porto Alegre, v.17, n.1, p. 20-30, 2009.

MORAES, R.; GALIAZZI, M. do C. Análise textual discursiva. Ijuí: Unijuí, 2007.

MORAES, R.; GALIAZZI, M. do C.; RAMOS, M. G. R. Pesquisa em sala de aula: fundamentos e pressupostos. In: MORAES, R.; LIMA, V. L. do R. (Org.). Pesquisa em sala de aula: tendências para a educação em novos tempos. Porto Alegre: EdiPUCRS, 2004.

MORAN, J. M. Ensino e aprendizagem inovadores em tecnologias audiovisuais e telemáticas. In: MORAN, J. M.; MASETTO, M. T.; BEHRENS, M. A. (Org.). Novas tecnologias e mediação pedagógica. Campinas: Papirus, 2001. p 11-65.

MOSER, F.; PORTANOVA, R. Criatividade e desafios nas aulas de matemática. In: BORGES, R. M. R.; BASSO, N. R. de S.; ROCHA FILHO, J. B. (Org.). Avaliação e interatividade na educação básica em ciências e matemática. Porto Alegre: EdiPUCRS, 2008.

NEUHAUS, V. A. da S.; ALMEIDA, V. F. C. O laboratório de matemática como recurso didático. In: VIII Encontro Nacional de Educação Matemática. Educação Matemática: um compromisso social. 2004.

NOVO, E. M. L. de M. Sensoriamento remoto: princípios e aplicações. São Paulo: Edgard Blücher. 308 p., 1999.

PAVANELLO, R. M. O abandono do ensino da geometria no Brasil: causas e consequências. Revista Zetetiké, Campinas, UNICAMP, n. 1, 1993, p.7-17.

SANTOS, B. M. C. Expomat - Exposição de Matemática. In: VIII Encontro Nacional de Educação Matemática. Educação Matemática: um compromisso social. 2004.

SANTOS, J. M.; LAHM, R. A.; BORGES, R. M. R. O sensoriamento remoto como recurso para a educação científica e tecnológica. In: BORGES, R. M. R.; BASSO, N. R. de S.; ROCHA FILHO, J. B. (Org.). Propostas interativas na educação científica e tecnológica. Porto Alegre: EdiPUCRS, 2008, v., p. 115-128.

VASCONCELOS, C. C. Ensino aprendizagem da matemática: velhos problemas, novos desafios. Revista Millenium, nº 20, São Paulo, 2009. 